\title{
Contribution of laser Doppler flowmetry with venoarteriolar reflex, cold, and rewarming testing, and intravital capillaroscopy to diagnose Raynaud's phenomenon
}

\author{
This article was published in the following Dove Press journal: \\ Journal of Vascular Diagnostics \\ 7 May 2014 \\ Number of times this article has been viewed
}

\author{
Jan Zeman' \\ Oksana Turyanytsya' \\ Vojtěch Kapsa² \\ Mojmír Eliášs \\ 'Department of Clinical Cardiology \\ and Angiology, Hospital Bulovka, \\ ${ }^{2}$ Charles University in Prague, \\ Faculty of Mathematics and Physics, \\ ${ }^{3}$ Kooperativa a.s., Pobrezni, Prague, \\ Czech Republic
}

\begin{abstract}
Background: The early differential diagnosis of Raynaud's phenomenon (RP) is crucial for the prognosis and therapy of these patients. In our microcirculatory laboratory, we use intravital capillaroscopy (IC), plethysmography (P), and laser Doppler flowmetry (LDF) for examining acrosyndromes. We combine LDF with venoarteriolar reflex test, cold test, and rewarming test to achieve more reliable diagnoses of acrosyndromes.

Patients and methods: We examined LDF and IC according to a strict protocol using a battery of tests (venoarteriolar reflex test, cold test, rewarming test) applied to five different groups of people and compared their results: healthy controls, primary Raynaud's phenomenon (PRP), systemic scleroderma, vibration white finger, and peripheral artery occlusive disease. Our tests included 340 individuals ( 72 patients plus 268 controls).

Results: Although all tests provided some differences between controls and patients, only the rewarming test offered significant results for differential diagnoses.

Conclusion: IC and LDF combined with the battery of tests (venoarteriolar reflex test, cold test, rewarming test) under standard conditions can be used as reliable tools to distinguish between PRP and some types of secondary RP (especially in the case of systemic scleroderma, vibration white fingers, or peripheral artery occlusive disease; RPs with organic occlusions of the small arteries causing the diseases). Our methodology can help to distinguish between other types of RP, as well.
\end{abstract}

Keywords: Raynaud's phenomenon, acrosyndrome, laser Doppler flowmetry, intravital capillaroscopy, scleroderma, vibration white finger, peripheral artery occlusive disease

\section{Introduction}

Raynaud's phenomenon (RP) is observed mostly as primary RP (PRP), a benign vasospastic disease. Conversely, secondary RP is a severe condition, but to diagnose the specific RP type requires an experienced clinician, with good laboratory background, and, in many cases, uncommon equipment, such as intravital capillaroscopy (IC), plethysmography (P), or laser Doppler flowmetry (LDF), and special procedures; for instance, biopsy, computed tomography, and angiography or magnetic resonance imaging. In many cases, clinicians may not observe all RP symptoms, and may only recognize paresthesias, non-typical color changes, or changing finger temperature limited to only some fingers. Incompletely manifested symptoms are often not diagnosed as RP but rather referred to as acrosyndrome in French sources. ${ }^{1}$ This practice is changing how frequently these decisive symptoms appear to occur in the population.
Correspondence: Mojmír Eliás Kooperativa, pojišt'ovna, a.s., Pobrežní 665/2I, I86 0I Praha 8, Czech Republic Email mojmir.elias@vig.cz 
RP occurs in 5\%-20\% of the population in Europe ${ }^{2}$ with a woman to man ratio of $4: 1,{ }^{2}$ while non-specific symptomatology is much more common (acrosyndrome).

The most important basic differential diagnosis is to distinguish between functional vasoactive diseases (usually vasospastic) and early stages of serious microcirculatory damage. The latter cause diseases with endothelial dysfunction ending in organic microcirculatory changes. ${ }^{3-9}$

The diagnostic algorithm we set up based on IC (Figure 1) has been used since 2009 with good results. However, LDF can be guided by IC, in that it can be used to identify the correct placement for measuring changes in the patient's hand. In this way, IC can contribute significantly to LDF efficiency used in standard testing.

We found it important to standardize test techniques during examinations; this includes hand placement in defined positions, and precise cooling and warming times and temperatures.

In the early stages of secondary RP we were able to confirm the diagnosis using this combination of methods, which, under other circumstances, would have been difficult. Over the years we have successfully developed a set of practical and robust testing methods.

\section{Materials and methods}

We examined consecutively incoming patients to our department between 2008-2011 with acrosyndromes assessed by IC and LDF with standard testing (venoarteriolar reflex [VAR], cold test, and rewarming test [Rt]) and compared them with healthy controls. The controls were examined in the regime of preventive entry examination provided for companies. Good compliance was necessary for enrolling them in the study, which meant providing a relevant patient history and an agreement to undergo repeated examinations. Next, we sorted participants into five groups as follows: Group 1, all participants had a negative history as a patient, negative clinical examination, and negative IC findings; Group 2, all patients with PRP had typical symptoms (symmetrical digiti mortui), normal IC findings, and normal screening laboratory tests. The diagnosis of PRP was proven by long term follow-up

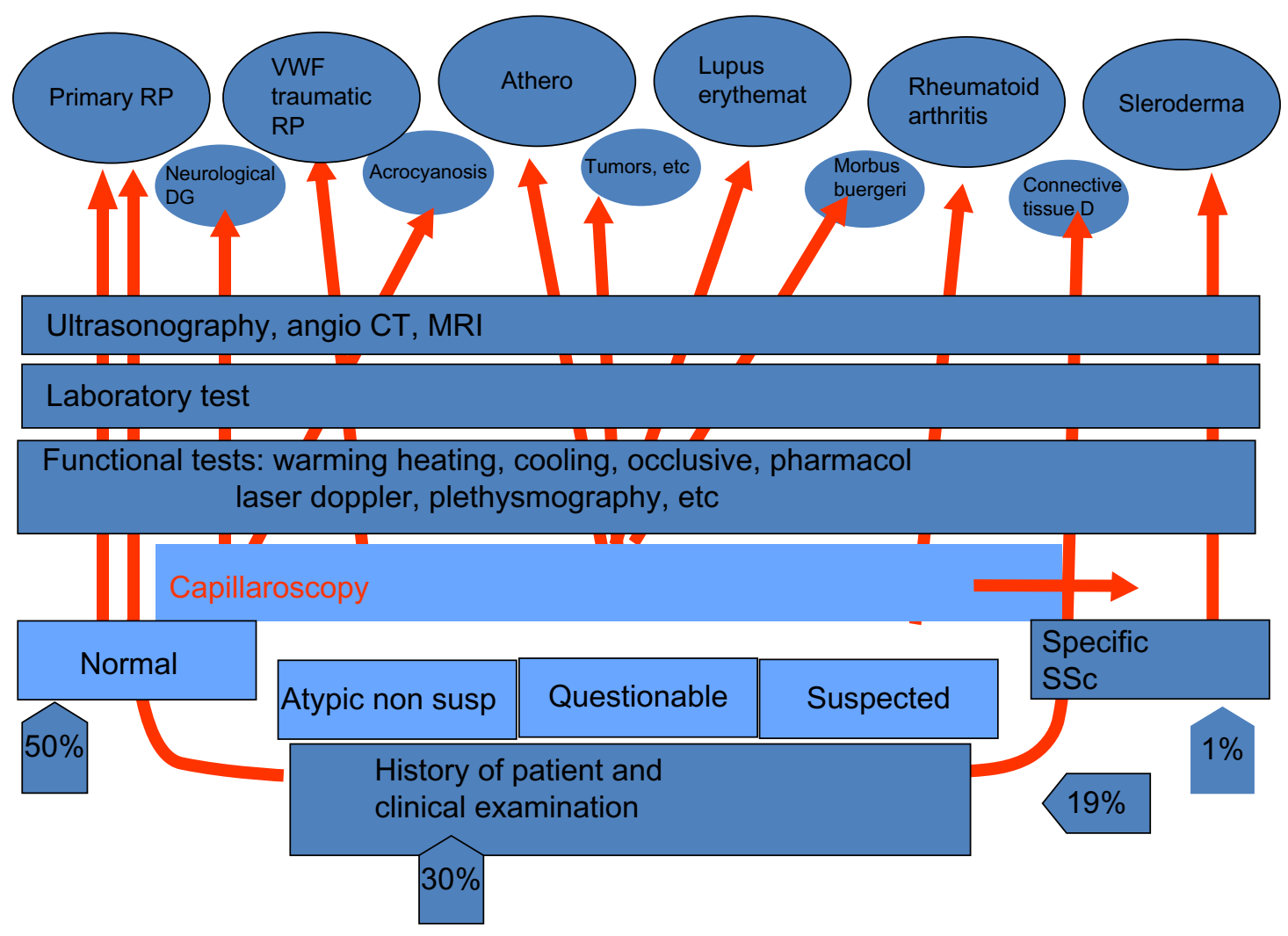

Figure I Diagnostic algorithm of Raynaud's phenomenon.

Notes: The algorithm is based on intravital capillaroscopy. History of patient and clinical examination with the help of capillaroscopy may differentiate in angiology ambulance minimally $50 \%$ of normal findings (healthy patients and patients with primary Raynaud's phenomenon). Thirty percent of cases with a questionable IC image require follow-up on a regular basis; 19\% of these cases require proper examination (lab tests, functional test, angiography, computed tomography, ultrasonography, and magnetic resonance imaging); and I\% leads us almost directly to the diagnosis. The algorithm has been used in our department since 2009.

Abbreviations: CT, computed tomography; D, disease; DG, diagnosis; erythemat, erythematosus; IC, intravital capillaroscopy; MRI, magnetic resonance imaging; PAOD, peripheral artery occlusive disease; Pharmacol, pharmacological test; PRP, primary Raynaud's phenomenon; RP, Raynaud's phenomenon; SSc, systemic scleroderma; susp, suspected; VWF, vibration white finger. 
of these patients, ie, for more than 2 years; Group 3, all patients had confirmed systemic scleroderma (SSc) according to the rheumatological convention and specific IC pictures; ${ }^{10}$ Group 4, patients had to have typical anamnestic data for vibration white finger (VWF) disease (blanching of finger and exposure to vibrating tools), neurological or musculoskeletal findings, and suspect IC images; Group 5, patients with proven ischemic arterial diseases (peripheral artery occlusive disease [PAOD]), positive angiography, magnetic resonance imaging angiography, and after partial amputations, clear internal, or surgical diagnosis their IC findings appear as "Stage A" of Bollinger and Fagrell criteria (distinct papillary capillaries filled with blood or micropools). ${ }^{11}$ Descriptions of the groups are provided in Table 1.

LDF examination was performed using the two channel machine MoorVMS-LDF (Moor Instruments, Millwey, Devon, United Kingdom) using the following parameters: wavelength $785 \mathrm{~nm} \pm 10 \mathrm{~nm}$, maximum accessible power $2.5 \mathrm{~mW}$, with flux (tissue perfusion), direct current (intensity), and concentration continuous measurement. The results are evaluated by special software provided together with the MoorVMS-LDF machine. Our IC equipment was a binocular microscope (Olympus Corporation, Tokyo, Japan) with possible enlargements $20-70 \times$ and photograph generating capabilities.

\section{Standard testing procedures}

All participants underwent a standard testing procedure as follows: after a 30 minutes rest in a quiet and comfortable room at the appropriate ambient temperature (approximately $23^{\circ} \mathrm{C}$ ) we recorded the basal flow. Flow measurement was taken at the approximate level of the heart. The shortest horizontal and smooth flow had to be measured for at least 2 minutes to be recorded. After that period, we performed the VAR test: a 1-minute measurement with one hand in the lower position ( $20 \mathrm{~cm}$ below the patient's heart) while the other remained in the initial position. The probe location was decided based on IC results (the most suspicious place). The

Table I Participant and group demographics

\begin{tabular}{llll}
\hline & Diagnosis & Male & Female \\
\hline Group 1 & Control & 208 & 60 \\
Group 2 & PRP & 7 & 25 \\
Group 3 & SSc & 2 & 10 \\
Group 4 & VWF & 16 & 0 \\
Group 5 & PAOD & 9 & 1 \\
\hline
\end{tabular}

Abbreviations: PAOD, peripheral artery occlusive disease; PRP, primary Raynaud's phenomenon; SSc, systemic scleroderma; VWF, vibration white finger. standard testing continued and flow in the basic rest position was determined.

After measurement under ambient temperatures, there was a cooling period induced by submerging the same hand and forearm in a special container filled with cold water at around $4^{\circ} \mathrm{C}$ (water with melting ice cubes) for 1-minute. This step can be arranged in several ways, as previously reported. ${ }^{12,13}$ Immediately after removing the hand from the container and putting it in the rest position, the Rt period began. At first there was a passive warming stage under ambient temperatures, then we finished the procedure with an active rewarming stage in $40^{\circ} \mathrm{C}$ water in another container. For the standard testing scheme and results, see Figures 2 and 3.

\section{Results}

Normal individuals (Group 1) had the greatest physiological undulating blood flow in the resting state, a good response to the VAR test ( $99 \%$ of Group 1 had positive VAR test results) with lowering of the blood flow after changing position of the hand, appropriate vasoconstrictive reaction during cooling, and a prompt recovery of the flow in the passive rewarming period (restoration of flow within 1-minute).

Nearly all patients with PRP (Group 2; 95\%) had normal (positive) VAR test results, commonly an intensive vasospastic reaction during the cooling test, and slower recovery (mostly more than 1-minute but shorter than 5 minutes) in the passive rewarming stage. The response to the active rewarming stimulus was sufficient. During our procedure, restitution of normal flow occurred within 5 minutes.

The patients with SSc (Group 3), VWF (Group 4), and PAOD (Group 5) had a lower basic flow and an uncertain reaction on the VAR test (around 60\% of positive cases overall in these groups; the percentage likely depends on the stage or how advanced each case is).

The diagnosis or the stage of the disease may influence response significance during the cooling period. However, the most important difference between Group 1, Group 2, and the other three groups was the insufficient prolonged response to the rewarming procedure.

The passive rewarming period (1-minute) can distinguish normal persons from patients with PRP with the highest sensitivity but lower specificity (Table 2). The result of the active rewarming procedure provides the biggest contribution to differential diagnosis. To achieve the best results, it is important to find an optimal ratio of heating to cooling periods. This displays balanced sensitivity and specificity of the method in the optimal range. Standard statistical results are provided in Table 2 . 


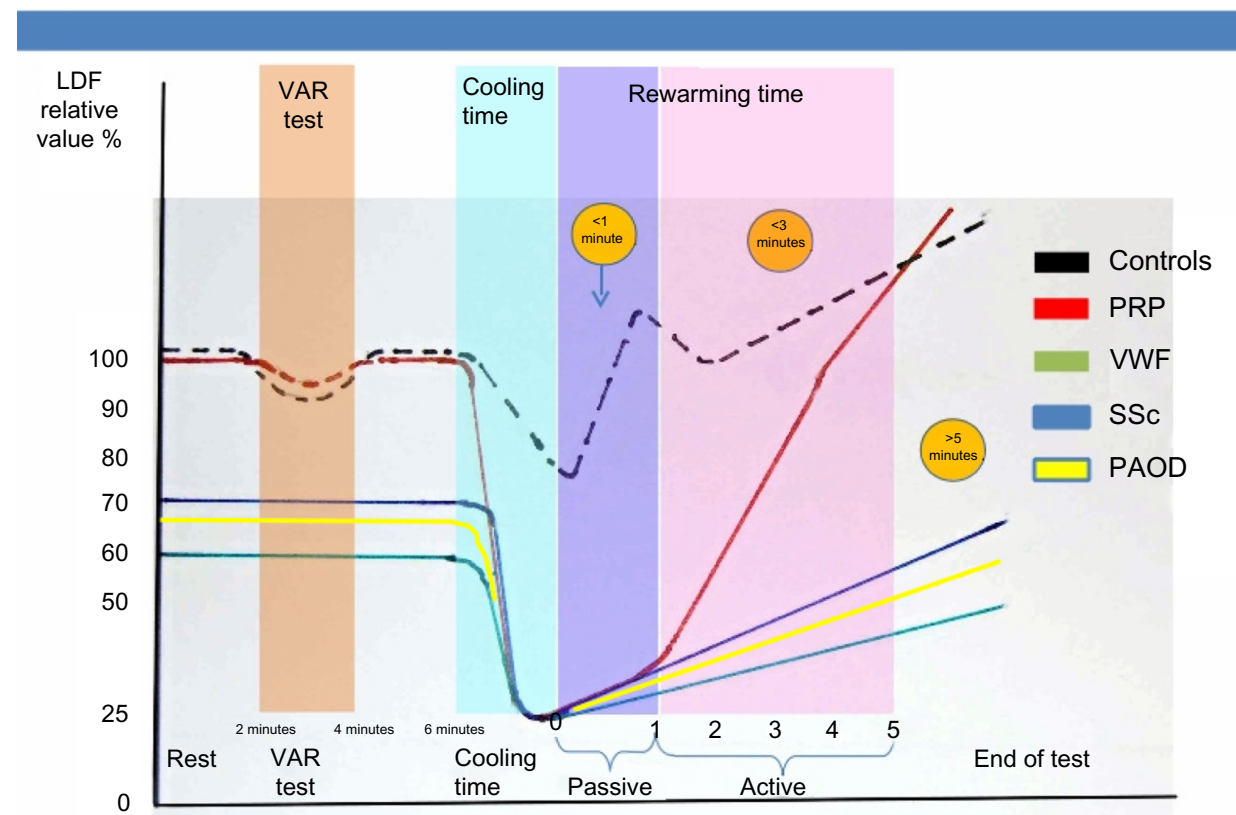

Figure 2 The relationship between time (horizontal) and average relative flow (vertical) during the battery of testing (VAR, cooling, and rewarming test LDF responses) for various diagnoses manifesting as Raynaud's phenomenon.

Notes: The LDF results are expressed in average units as the angle of laser beam cannot be exactly calculated in relation to the micro-circulation net.

Abbreviations: LDF, laser doppler flowmetry; PAOD, peripheral artery occlusive disease; PRP, primary Raynaud's phenomenon; SSc, systemic scleroderma; VAR, venoarteriolar reflex test; $\mathrm{VWF}$, vibration white finger.

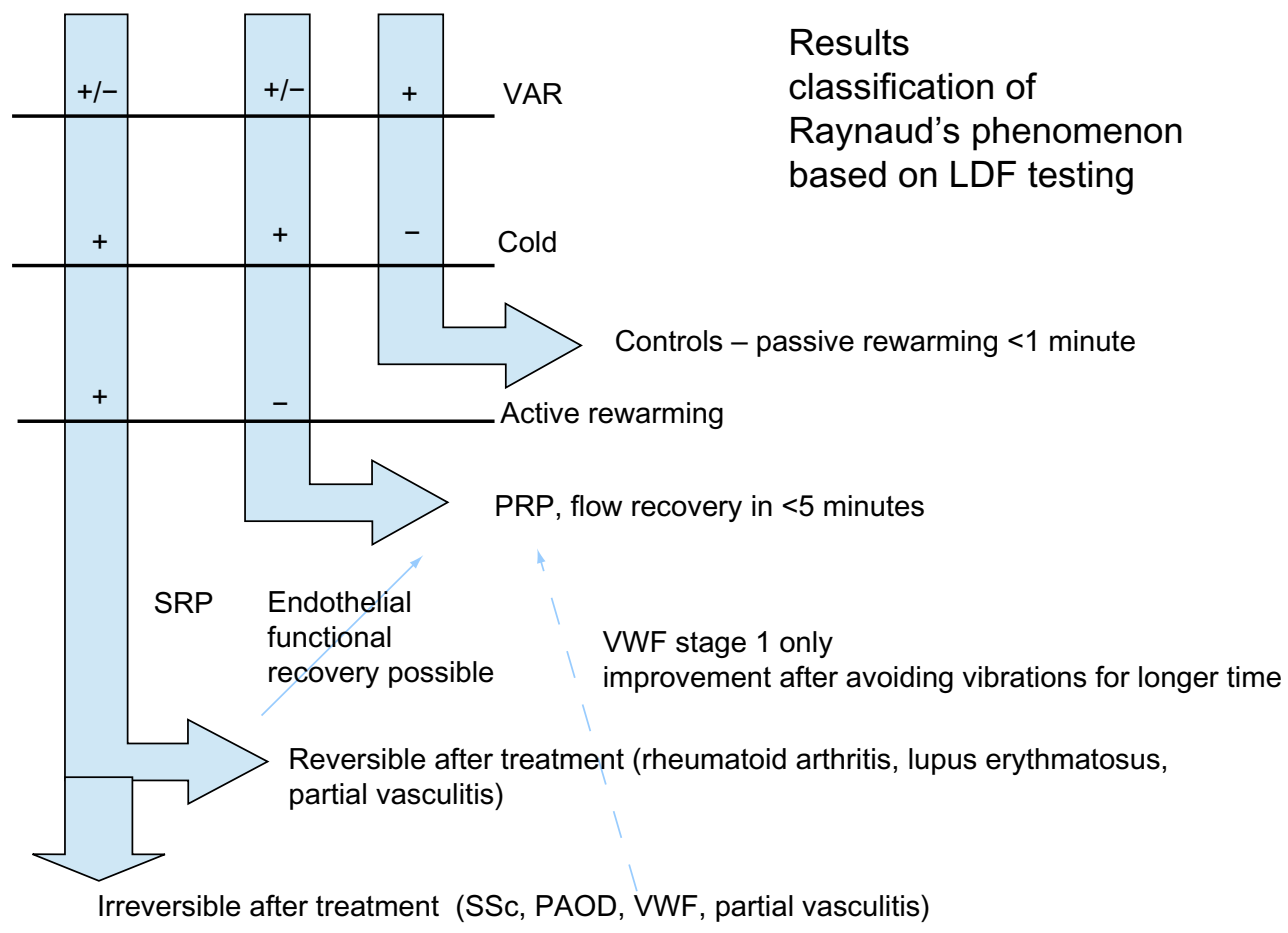

Figure 3 Schema of how to interpret the test results for different diagnoses. The schema clearly shows that the most important discriminating procedure is the rewarming test. The finer classification of the underlying diagnosis is difficult when only using LDF; intravital capillaroscopy can contribute to elucidating the correct diagnosis.

Abbreviations: LDF, laser doppler flowmetry; PAOD, peripheral artery occlusive disease; PRP, primary Raynaud's phenomenon; SRP, secondary Raynaud's phenomenon; SSc, systemic scleroderma; VAR, venoarteriolar reflex test; VWF, vibration white finger. 
Table 2 Standard statistics

\begin{tabular}{|c|c|c|c|c|c|}
\hline & PRP & SSc & VWF & PAOD & Controls \\
\hline Positive & 30 & II & 13 & 8 & 2 \\
\hline Negative & 2 & I & 3 & 2 & 266 \\
\hline Total & 32 & 12 & 16 & 10 & 268 \\
\hline Sensitivity & $93.75 \%$ & $91.67 \%$ & $81.25 \%$ & $80.00 \%$ & \\
\hline Specificity & & & & & $99.25 \%$ \\
\hline $\begin{array}{l}\text { Positive predictive } \\
\text { value }\end{array}$ & $93.75 \%$ & $84.62 \%$ & $86.67 \%$ & $80.00 \%$ & \\
\hline $\begin{array}{l}\text { Negative predictive } \\
\text { value }\end{array}$ & & & & & $97.08 \%$ \\
\hline$\chi^{2}$ & 281 & & & & \\
\hline$P$-value & 0.000 & & & & \\
\hline Degrees of freedom & 4 & & & & \\
\hline
\end{tabular}

\section{Discussion}

Our explanations for the false negative results in the standard testing arrangement used in this study are the following:

1. The stage of some diseases; for example, in the very early stage of SSc we can place the probe on a relatively healthy location on a finger. IC can sometimes help to determine the worst region for placing the probe. On the other hand, when we have a very advanced and poor blood supply, the response to the cold can be relatively small (a small change when we compare minimal flow during rest to the lower, near zero, flow during the cooling period). IC can clearly indicate when the blood flow stops and how long it takes to start perfusing the skin again. This is the reason why IC assistance is important for improving the sensitivity and specificity of LDF testing.

2. Extreme weather conditions. It is necessary to report that we have more positive results (especially in the PRP cases) during the winter time than during the hot summer. Resting in the standard temperature room for half an hour before testing is probably too short to normalize body temperate during rare extreme weather conditions, but from a practical point of view it is difficult to prolong the rest period to 1 or 2 hours; such an examination in the hospital would require maintaining a room with proper ambient temperature for 2 or 3 hours, which is hard to obtain and justify, especially for testing individuals with minimal symptoms.

3. Test quality. We must stress the importance of the strict, accurate regime of testing for identifying relevant results. It is especially important to ensure that the time of the heating period is consistent in order to obtain a sufficient specificity of the testing, as, for example, a longer heating period of just 5 minutes lowers the specificity (approximately 5\% per minute), which changes the sensitivity of the testing.
Interesting, yet inconsistent, results of this study included identifying patients with lupus erythematosus or rheumatoid arthritis. The reason for this result may be attributable to the small number of cases we tested. Conversely, it may be a result of the fact that $10 \%$ or $20 \%$ of patients suffering from rheumatoid arthritis have microcirculation expression like RP. It seems that the results of LDF testing depend on the treatment effect, ${ }^{14}$ as sometimes we can see improvement or findings during remission for these patients. This means that for the purposes of direct diagnostics of other RPs this testing battery cannot contribute significantly.

LDF guided by IC offers further possibilities for accurately diagnosing secondary RP. We would like to continue research in this area, using ideas and methods that can be found in other studies. ${ }^{15-26}$

\section{Conclusion}

We believe that we have established a relatively robust and reliable examination schema for the differential diagnosis of RP. Furthermore, we believe that most patients will be amenable to this battery of testing though there can exist some exceptions of rare intolerance to the intensive cooling test.

The place where the LDF probe should be placed has to be determined by IC prior to the LDF. Also, keeping the proper sequence and timing of the cooling and rewarming periods is crucial for success.

This procedure was tested with good results for the limited purpose of diagnosing secondary RP as discussed, but not for many others, such as rheumatoid arthritis, lupus erythematosus, and so on. These diagnoses require their own specific procedures especially the correct rewarming periods.

\section{Disclosure}

The authors report no conflicts of interest in this work.

\section{References}

1. Acrosyndrome [website on the Internet]. Wikipedia; 2014. Available from: http://fr.wikipedia.org/wiki/Acrosyndrome. Accessed December 29, 2013. French.

2. Heidrich H. Functional vascular diseases: Raynaud's syndrome, acrocyanosis and erythromelalgia. Vasa. 2010;39(1):33-41.

3. Ziegler S, Gschwandtner M, Zöch C, et al. Laser Doppler anemometry distinguishes primary Raynaud phenomenon from VWF syndrome. Microvasc Res. 2004;68(3):203-208.

4. Del Bianco E, Magini B, Muscarella G, Cappugi P, Lotti T. Raynaud's phenomenon (primary or secondary to systemic sclerosis). The usefulness of laser-Doppler flowmetry in the diagnosis. Int Angiol. 2001;20(4) 307-313.

5. Grattagliano V, Iannone F, Praino E, et al. Digital laser doppler flowmetry may discriminate "limited" from "diffuse" systemic sclerosis. Microvasc Res. 2010;80(2):221-226. 
6. Jadhav ST, Ferrell WR, Petrie JR, et al. Microvascular function, metabolic syndrome, and novel risk factor status in women with cardiac syndrome X. Am J Cardiol. 2006;97(12):1727-1731.

7. Wigley FM, Wise RA, Mikdashi J, Schaefer S, Spence RJ. The post-occlusive hyperemic response in patients with systemic sclerosis. Arthritis Rheum. 1990;33(11):1620-1625.

8. Murray AK, Moore TL, King TA, Herrick AL. Abnormal microvascular response is localized to the digits in patients with systemic sclerosis. Arthritis Rheum. 2006;54(6):1952-1960.

9. Ozbebit FY, Esen F, Güleç S, Esen H. Evaluation of forearm microvascular blood flow regulation by laser Doppler flowmetry, iontophoresis, and curve analysis: contribution of axon reflex. Microvasc Res. 2004;67(3):207-214.

10. Maricq HR. Widefield capillary microscopy. Technique and rating scale for abnormalities seen in scleroderma and related disorders. Arthritis Rheum. 1981;24(9):1159-1165.

11. Bollinger A, Fagrell B. Clinical Capillaroscopy. 1st ed. Toronto: Hogrefe and Huber Publishers; 1990:65-68.

12. Pyykkö I, Färkkilä M, Korhonen O, Starck J, Jäntti V. Cold provocation tests in the evaluation of vibration-induced white finger. Scand J Work Environ Health. 1986;12(4 Spec No):254-258.

13. Lütolf O, Chen D, Zehnder T, Mahler F. Influence of local finger cooling on laser Doppler flux and nailfold capillary blood flow velocity in normal subjects and in patients with Raynaud's phenomenon. Microvasc Res. 1993;46(3):374-382.

14. Datta D, Ferrell WR, Sturrock RD, Jadhav ST, Sattar N. Inflammatory suppression rapidly attenuates microvascular dysfunction in rheumatoid arthritis. Atherosclerosis. 2007;192(2):391-395.

15. Allen JA, Devlin MA, McGrann S, Doherty CC. An objective test for the diagnosis and grading of vasospasm in patients with Raynaud's syndrome. Clin Sci (Lond). 1992;82(5):529-534.

16. Bircher A, de Boer EM, Agner T, Wahlberg JE, Serup J. Guidelines for measurement of cutaneous blood flow by laser Doppler flowmetry. A report from the Standardization Group of the European Society of Contact Dermatitis. Contact Dermatitis. 1994;30(2):65-72.
17. Ekenvall L, Lindblad LE. Vibration white finger and digital systolic pressure during cooling. Br J Ind Med. 1986;43(4):280-283.

18. Lau CS, Khan F, Brown R, McCallum P, Belch JJ. Digital blood flow response to body warming, cooling, and rewarming in patients with Raynaud's phenomenon. Angiology. 1995;46(1):1-10.

19. Mahbub M, Harada N. Review of different quantification methods for the diagnosis of digital vascular abnormalities in hand-arm vibration syndrome. J Occup Health. 2011;53(4):241-249.

20. Murray AK, Moore TL, Manning JB, Taylor C, Griffiths CE, Herrick AL. Noninvasive imaging techniques in the assessment of scleroderma spectrum disorders. Arthritis Rheum. 2009;61(8):1103-1111.

21. Pope J, Harding S, Khimdas S, Bonner A, Baron M; Canadian Scleroderma Research Group. Agreement with guidelines from a large database for management of systemic sclerosis: results from the Canadian Scleroderma Research Group. J Rheumatol. 2012;39(3): 524-531.

22. Schlager O, Gschwandtner ME, Herberg K, et al. Correlation of infrared thermography and skin perfusion in Raynaud patients and in healthy controls. Microvasc Res. 2010;80(1):54-57.

23. Stoyneva Z. Laser Doppler-recorded venoarteriolar reflex in Raynaud's phenomenon. Auton Neurosci. 2004;116(1-2):62-68.

24. Stoyneva Z, Lyapina M, Tzvetkov D, Vodenicharov E. Current pathophysiological views on vibration-induced Raynaud's phenomenon. Cardiovasc Res. 2003;57(3):615-624.

25. Wahlberg E, Olofsson P, Swedenborg J, Fagrell B. Level of arterial obstruction in patients with peripheral arterial occlusive disease (PAOD) determined by laser Doppler fluxmetry. Eur J Vasc Surg. 1993;7(6): 684-689.

26. Welsh CL. Digital rewarming time in the assessment of vibration-induced white finger. Scand J Work Environ Health. 1986;12(4):249-250.
Journal of Vascular Diagnostics

\section{Publish your work in this journal}

Journal of Vascular Diagnostics is an international, peer-reviewed journal of diagnostics, focusing on non invasive vascular investigation methods involved in the evaluation of vascular diseases. The journal is committed to the rapid publication in the fields of vascular diseases. Original research, review, case reports, expert opinion and commentaries

\section{Dovepress}

are all considered for publication. The manuscript management system is completely online and includes a very quick and fair peer-review system, which is all easy to use. Visit http://www.dovepress.com/testimonials.php to read real quotes from published authors. 